\title{
Lazar Continuous Carbon Baking - the Future is Now
}

\author{
Nicholas Walla \\ Steven J. Dubec ${ }^{a}$ and Rick Lazarou ${ }^{* b}$ \\ ${ }^{a}$ Lazar Anode Technologies, LLC \\ 1765 River Road, Hawesville, KY 42348, USA \\ ${ }^{b}$ Lazar Anode Technologies, $A G$ \\ Schiller 21, 6440 Brunnen, Switzerland
}

Received 21.02.2016, received in revised form 12.04.2016, accepted 13.06.2016

The Lazar Continuous Carbon Baking Furnace (CCBF) presents a groundbreaking new process for the baking of carbon anodes. A static thermal profile provides a consistent heat-up rate across distinct temperature zones, eliminating thermal cycling. Complete PAH destruction, combined with the lack of thermal cycling, eliminates refractory maintenance requirements and allows for tighter tolerances in pollution-control systems, leading to a significant decrease in operating costs. Costs to build a Lazar CCBF are estimated to be 35 to $45 \%$ less than conventional ringtype furnaces, with operating costs estimated to be approximately $60 \%$ less.

Keywords: anode baking, carbon anodes, continuous carbon baking, Lazar CCBF.

Citation: Walla N., Dubec S.J., Lazarou R. Lazar continuous carbon baking - the future is now, J. Sib. Fed. Univ. Eng. technol., 2016, 9(5), 693-672. DOI: 10.17516/1999-494X-2016-9-5-693-702.

(C) Siberian Federal University. All rights reserved

* Corresponding author E-mail address: Rick.Lazarou@LazarAnodeTech.com 


\title{
Непрерывный обжиг угольных анодов \\ по технологии Lazar - будущее сегодня
}

\author{
Николас Вола ${ }^{\mathrm{a}}$ Стивен Дж. Дубек ${ }^{\mathrm{a}}$ Рик Лазароуб \\ ${ }^{a}$ Lazar Anode Technologies, LLC \\ 1765 River Road, Hawesville, KY 42348, USA \\ ${ }^{6}$ Lazar Anode Technologies, $A G$ \\ Schiller 21, 6440 Brunnen, Switzerland
}

Печь непрерывного действия Lazar реализует новый перспективный процесс обжига угольных анодов. Статический тепловой профиль обеспечивает стабильную скорость нагрева в определенных температурных зонах, устраняя необходимость тепловых ииклов. Полное разрушение ПАУ наряду с отсутствием необходимости тепловых ииклов устраняет необходимость обслуживания футеровки и обеспечивает более строгое соблюдение допусков в системах контроля выбросов, что существенно снижает производственные расходы. Затраты на создание печи непрерывного действия Lazar на 35-45 \% меньше, чем на традиционные кольцевые печи; затраты на их эксплуатацию примерно на 60 \% ниже.

Ключевые слова: обжиг анодов, угольные аноды, непрерывный процесс обжига, печь непрерывного действия Lazar.

\section{Introduction}

Two major factors continue to retard the growth of the global aluminum industry: prohibitive costs for new facilities or upgrades and environmental restrictions. High costs can prevent much needed capacity expansion or replacement of obsolete processes. Similarly, environmental requirements vary from between nations, with some limitations entirely preventing the construction of new facilities. This paper will describe the Lazar Continuous Carbon Baking Furnace (CCBF), a vertically oriented furnace that presents a cleaner, low-cost alternative to traditional carbon-baking technologies.

\section{Background}

Nearly all primary aluminum production is done by facilities using the Hall-Héroult process, which uses high-current electrolysis to reduce alumina $\left(\mathrm{Al}_{2} \mathrm{O}_{3}\right)$ into liquid aluminum within electrolysis cells. This electrolysis requires the use of carbon anodes, which are consumed during the process. The aluminum industry currently uses one of two anode types in its cells: Söderberg continuous anodes and prebaked anodes.

\section{Söderberg Anodes}

Processes that use Söderberg cells input a continuous supply of carbon and coal tar pitch into the top of the electrolysis cell. This mixture is then baked by the high temperatures found within the cell. The continuous feeding of anode material is required to replace that which is consumed by the process.

\section{Prebaked Anodes}

A prebaked anode is created by forming the mixture of carbon (petroleum coke) and coal tar pitch within a mold. The shaped anode is then baked at high temperatures (over $1000^{\circ} \mathrm{C}$ ). The prebaked 
anode then has metal rods attached to it. During use, the anode (attached via the rods to a busbar) is lowered into the cell. Once the anode is approximately $80 \%$ consumed, the remaining material is removed, cleaned, and recycled.

\section{Advantages and Disadvantages}

While the Söderberg technology eliminates the need for a separate baking procedure, the process emits large amounts of polyaromatic hydrocarbons (PAHs) into the environment. In a prebake furnace, some of those PAHs are destroyed. However, the traditional method for baking carbon anodes - the ring furnace - has much higher costs associated with it when compared to using Söderberg technology.

Both technologies are still in use today, though a majority of primary aluminum production uses the prebaked technology (roughly one-third of global primary aluminum production uses Söderberg technology [1]). The large majority of new primary aluminum facilities are constructed to use prebaked anode cells rather then Söderberg. However, the high cost for prebaked systems (especially the ring furnace) has slowed the rate of conversion from Söderberg to prebake technology.

\section{Lazar ccbf}

The Lazar CCBF introduces a new method for the baking of carbon anodes. Rather than the horizontal batch process of the traditional ring furnace, the Lazar CCBF is a vertical furnace that continuously bakes moving columns of anodes. In addition to the elimination of fire cycles, the Lazar CCBF completely destroys the PAHs that emit from the anodes during the baking process. A diagram of the Lazar CCBF concept is shown below in Fig. 1.

Advantages. The Lazar CCBF is designed to offer many advantages over traditional anode baking methods. These advantages are necessary to overcome some of the biggest issues faced by primary

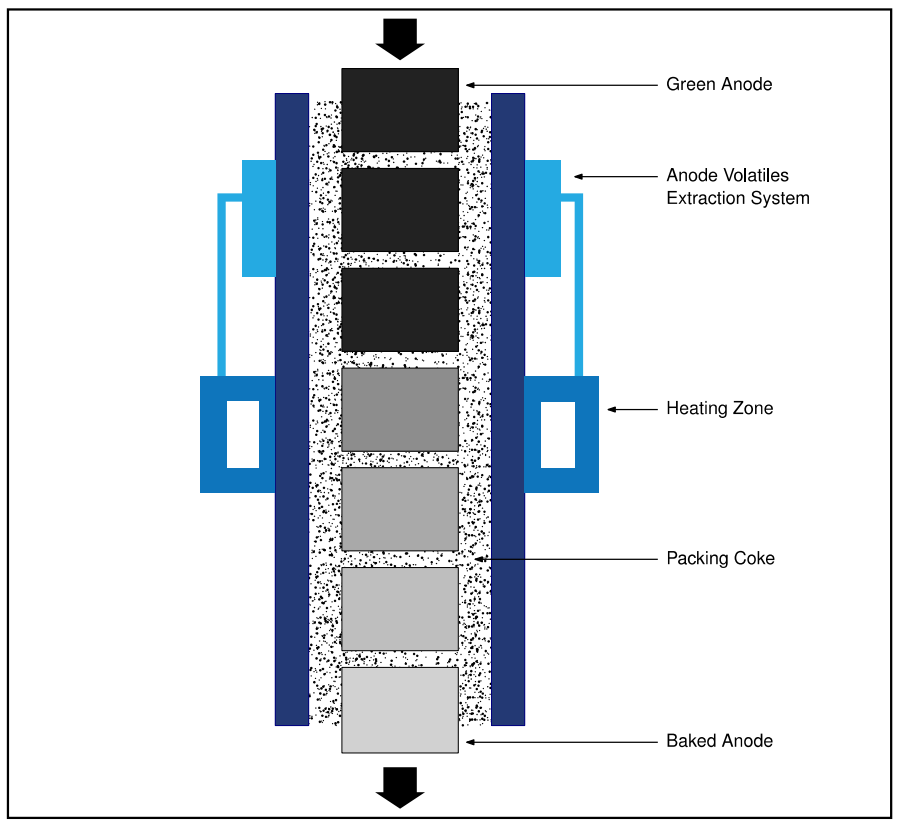

Fig. 1. Diagram showing Lazar CCBF concept 
aluminum, which often lead to the requirement of using third-party anodes. The issues include cost feasibility on expanding existing anode plants to meet increased cell capacity, regular repair and maintenance requirements on bake furnaces, costs to build bake facilities at plants that have been converted from Söderberg cells to prebake cells, and severe environmental restrictions (e.g. Iceland) [2]. Eliminating or altogether avoiding these issues removes many of the factors that limit the growth of the primary aluminum industry.

Flexibility. The design of the Lazar CCBF allows for an inherent control over many aspects of anode baking without the need to change the design of furnace itself. Process output capability, anode sizing, temperature levels, and anode heat-up rate can be modified to meet specific needs.

\section{Non-contiguous modular design}

A key improvement in the Lazar CCBF over traditional anode baking methods is the modularity in design. This modularity allows a facility to build additional furnaces as needed to meet increased capacity needs. Furnaces can also be built in a disconnected fashion, allowing for optimized placement with regards to production needs. Fig. 2 and 3 below demonstrate this concept.

Shows a 3D rendering of a full-scale CCBF consisting of three anode-processing units (four pits each, twelve anodes high) in comparison with two full-scale CCBF with 48 anode-processing units. Additional capacity can be added to a unit after construction with minimal changes to the existing unit.

Fig. 2 demonstrates the greatly reduced footprint required by the Lazar CCBF, with the two full production units shown within the footprint of an equivalent ring furnace. Those two units, with a footprint of $1100 \mathrm{~m}^{2}$ [3] (versus roughly $5425 \mathrm{~m}^{2}$ for the ring furnace) are capable of providing a continuous supply of anodes to meet the requirements of a 250ktpa aluminum smelter [3].

\section{Temperature control}

One of the major advantages of the Lazar CCBF over traditional anode baking technologies is the elimination of thermal cycling. The Lazar CCBF features stationary burners that maintain a steady-

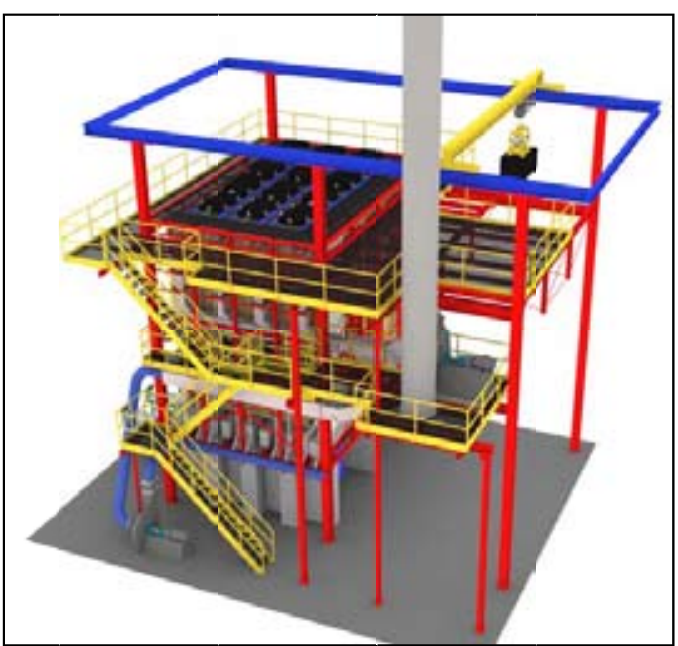

a

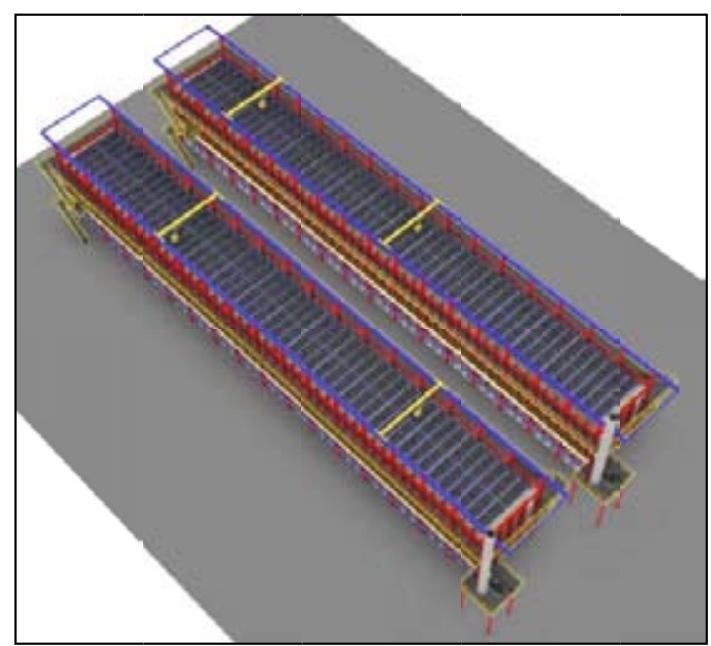

b

Fig. 2. Model of a three unit CCBF (a) and two 48 unit CCBF (b) 


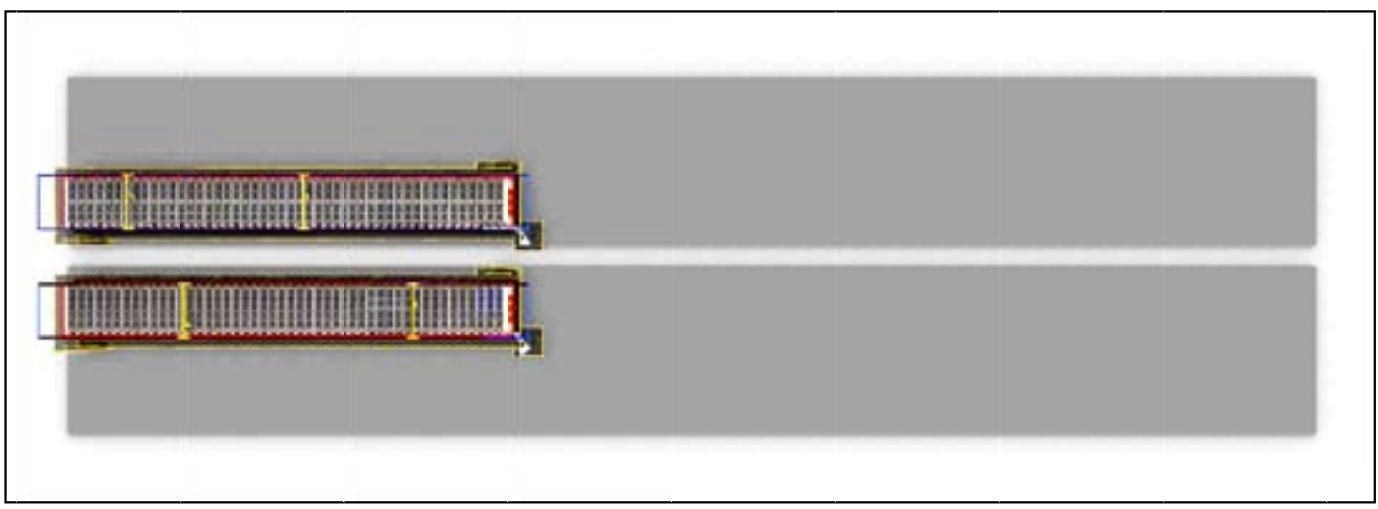

Fig. 3. Footprint comparison between two 48 unit CCBF (modeled) and an equivalent open top ring furnace (shaded footprint)

state thermal profile. Each anode passing through the CCBF experiences nearly-identical heat-up rates. The isotherm sizes and values can be adjusted to meet the specific requirements of a facility. Additionally, temperatures within a furnace need not be consistent across all anode-processing units within a single $\mathrm{CCBF}$ allowing various production types to occur simultaneously. This allows a single furnace to meet the needs of a facility using multiple anode shapes.

\section{Process rates}

In addition to altering the thermal profile of the furnace, the heat-up rate can be further modified through the alteration of anode movement. The heating profile within the furnace can therefore be "expanded" or "contracted" with slower or faster anode movement rates, respectively. For facilities with varied anode shape requirements, processing rates can be modified on a per-pit basis, allowing larger or smaller anodes to easily experience different residence times within the furnace. This also enables anodes to be unloaded from the furnace at desired temperatures with much greater precision.

\section{Integration with new technologies}

The flexibility and modularity of the Lazar CCBF also invites new interactions with associated aspects of primary aluminum production. The ability to enact just-in-time (JIT) delivery of anodes can greatly reduce the need for storage space and simplify the implementation of new technologies such as hot rodding (rodding of prebaked anodes while still at high-temperature to reduce thermal shock on introduction to a cell).

\section{Automation and Monitoring}

The continuous/consistent output and steady-state thermal conditions of the Lazar CCBF enable high degrees of automation. The task of loading anodes into the CCBF is performed by an automated single-purpose indexing crane, with anodes exiting the furnace via conveyers. Similarly, packing coke enters the top of the CCBF through an automated system that maintains required levels and is unloaded at the bottom of the furnace through the assistance of gravity.

$$
-697-
$$


Control systems with Human-Machine Interfaces (HMI) allow the process to be continuously monitored and adjusted if needed. This is made easier due to the steady-state nature of the furnace, where values need only be maintained and monitored, not frequently adjusted. In a traditional bake furnace, human error and insufficient process knowledge can result in avoidable costs of as much as one million USD per annum at a 100ktpa facility [4]. By removing steps within the anode baking process that require human intervention or control, these costs can be reduced or even eliminated.

\section{Environment and Safety}

A primary focus during the development of the Lazar CCBF was improved environmental and safety performance relative to traditional anode technologies. Important factors in this effort were the elimination of PAH emissions, tighter tolerance for emissions scrubbing, and a safer work environment.

\section{Burns PAH}

During the baking process, carbon anodes bound by coal tar pitch emit various polyaromatic hydrocarbons. In Söderberg and ring furnace prebake technologies, these emissions must be scrubbed from process exhaust or be exhausted into the atmosphere. The Lazar CCBF instead pulls the PAH emissions through the packing coke and into collection chambers. The PAHs are then directed into the primary combustion system, thus fueling the process. The PAHs therefore nearly eliminate the need for fuel once the process has reached steady-state.

\section{Consistent output}

The continuous and steady-state nature of the Lazar CCBF baking process inherently results in a consistent output of emissions. Unlike the major swings in emission rates seen by a cyclic process, steady-state operation allows for tighter tolerances in scrubbing systems for fluoride emissions. This allows a facility to lower costs associated with the selection of scrubbing systems or even determine if the emissions from the Lazar CCBF can be directed into existing scrubbing systems.

\section{Worker safety}

Many intrinsic features of the Lazar CCBF support occupational health \& safety (OH\&S) efforts. The elimination of harmful ceramic fibers, a low temperature within the work environment, and the destruction of PAH emissions all serve to create a cleaner, safer work environment.

\section{Costs}

For new facilities, facility conversion (Söderberg to prebake), and facility retrofitting (ring type to CCBF), the Lazar CCBF fundamentally reduces the costs associated with anode baking. These costs reductions come in the form of both capital expenditure (CAPEX) savings and operational expenditure (OPEX) savings.

\section{CAPEX Savings}

There are several capital advantages to the implementation of the Lazar CCBF when compared to the traditional ring type furnace. These include lower costs for construction due to a lower refractory 
requirement that is $50 \%$ of that required by a ring type furnace. As mentioned before, the improved environmental control through the continuous consistent output and complete PAH destruction lowers the costs associated with pollution control equipment.

Due to the gravity assisted unloading of anodes and packing coke, the need for large multipurpose cranes is also eliminated, with the Lazar CCBF only requiring simple single-purpose cranes. This also removes many of the structural requirements that are associated with multi-purpose cranes. These factors combine to offer an estimated 35-45 \% lower CAPEX requirement than an equivalent traditional ring type furnace [5]

\section{OPEX Savings}

Many of the continual costs associated with traditional anode backing technologies are reduced or even eliminated with the Lazar CCBF. With the elimination of fire cycles, there is a significant reduction in refractory maintenance and periodic partial or complete rebuilds. The replacement of multi-purpose cranes with single-purpose cranes greatly reduces expensive crane maintenance. The process also consumes less packing coke and, with the complete PAH extraction and destruction, lowers natural gas usage. Increased automation also reduces personnel requirements, further lowering OPEX costs.

A visual comparison of the Lazar CCBF to existing anode baking technologies is shown below in Fig. 3. The Lazar CCBF process is shown on the left with a comparison to existing prebake technologies

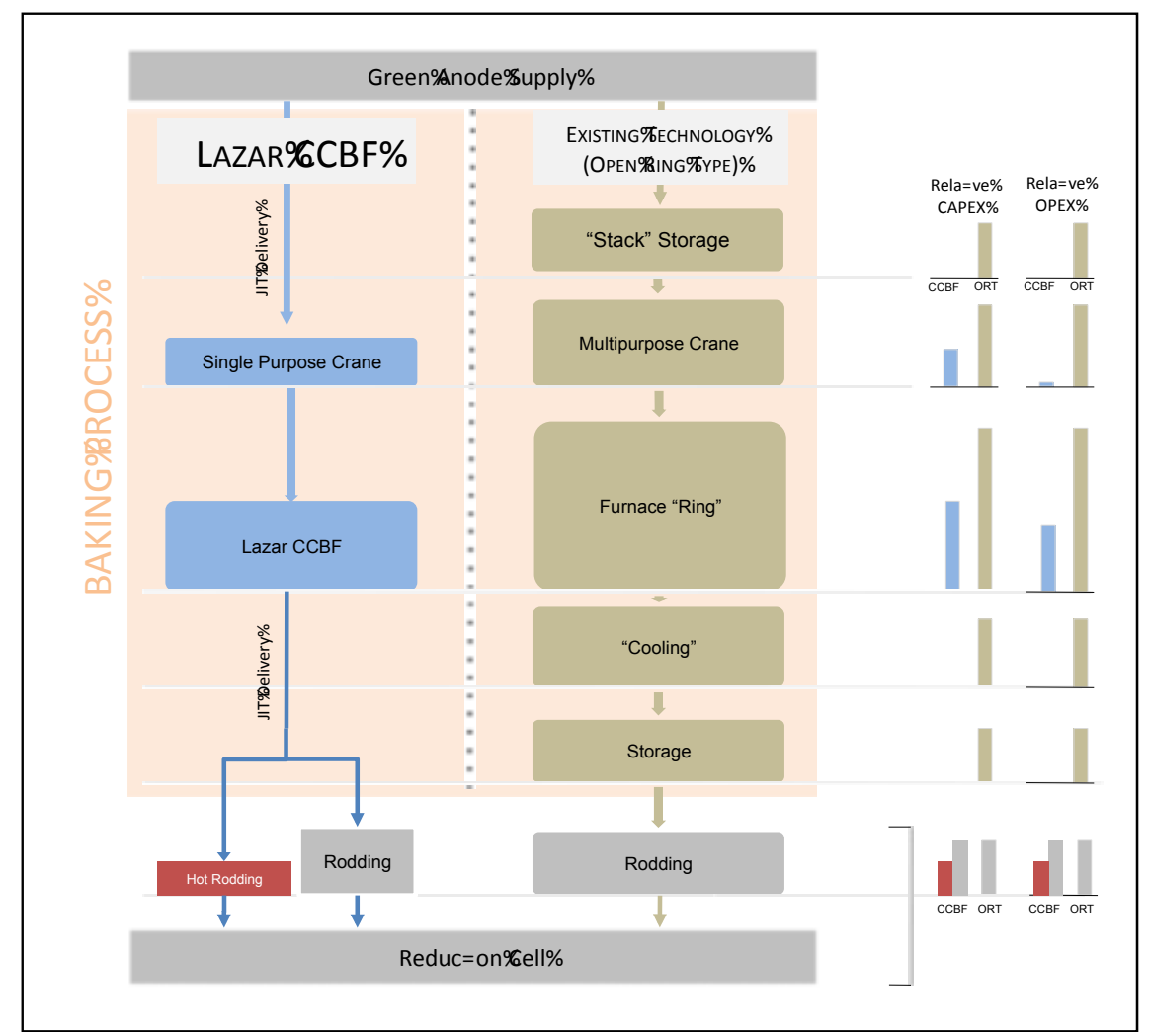

Fig. 4. Diagram showing costs comparison between Lazar CCBF and existing technologies 
(open ring type furnaces) on the right. As shown in the image, the Lazar CCBF enables JIT delivery and the ability to unload anodes at desired temperatures, reducing or eliminating much of the storage requirements. The relative costs of the single purpose crane and the CCBF itself are also shown in comparison to the multipurpose crane and the ring furnace. The diagram also displays how the Lazar CCBF can be integrated into other technologies, such as hot rodding.

\section{Research and Development}

The research and development of the Lazar CCBF began in 2006 with a proof-of-concept facility (pictured below in Fig. 4). The purpose of this facility was to demonstrate the extraction of PAHs from a vertical column of anodes, heating anodes up to temperatures where volatiles are emitted, but not to full baking temperatures. The test was successful, with the PAHs being released from the baking anodes and passing through the packing coke into collection chambers. The facility also verified the methods for moving the anode stacks vertically.

Prior to the construction of a full-scale prototype facility, computational fluid dynamics (CFD) simulations were performed on the proposed design [6]. These simulations provided an analysis of the thermal profile expected in a furnace reaching full baking temperatures, some of which is shown below in Fig. 5. Of note in the right image of Fig. $\mathbf{5}$ is the nearly identical profile across four different anode columns, as seen in the centerline plot. Simulations included the movement of the anodes and packing coke, as well as an analysis of the isotherms at various temperature rates. Through the results of parametric studies, it was possible to optimize various operating and design conditions of the prototype facility.

\section{Prototype facility}

Using the results information obtained from the proof-of-concept facility and the CFD study optimizations, a full-scale prototype facility was built in Hawesville, KY, USA. This prototype facility,

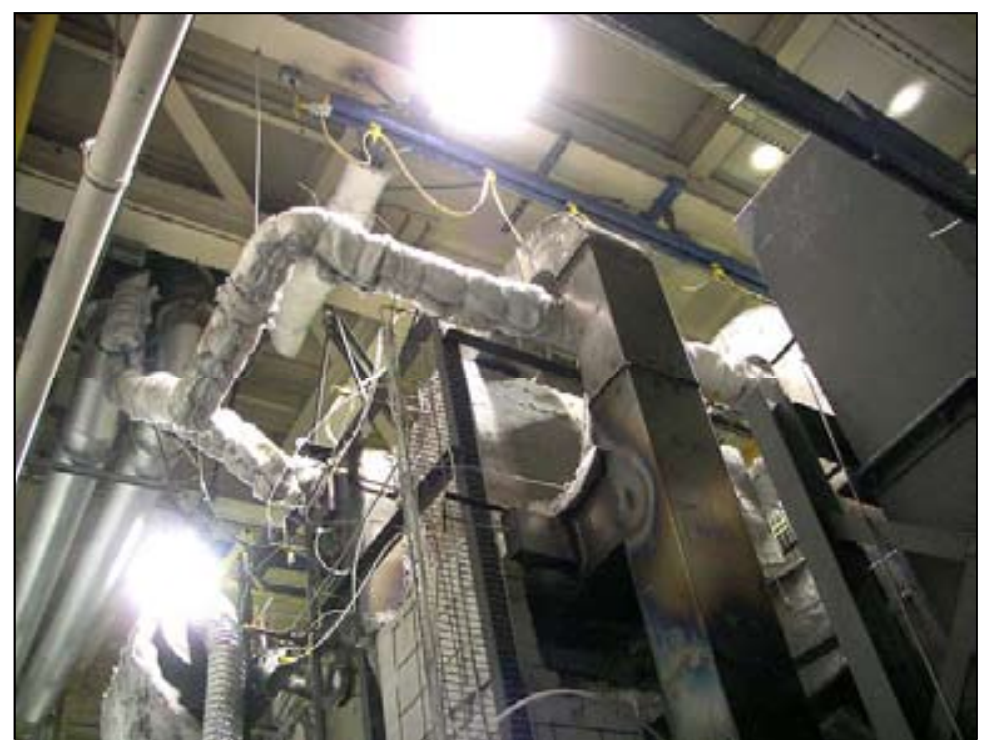

Fig. 5. Proof-of-Concept CCBF facility 
pictured below in Fig. 7 Fig. 6, serves as a research and development CCBF capable of producing anodes for a primary aluminum production facility. The furnace features three anode-processing units with four columns each.

The facility serves to optimize the process on a full scale. As a research and development facility, testing is done to demonstrate reduced energy consumption, improved anode quality, and benchmark



a

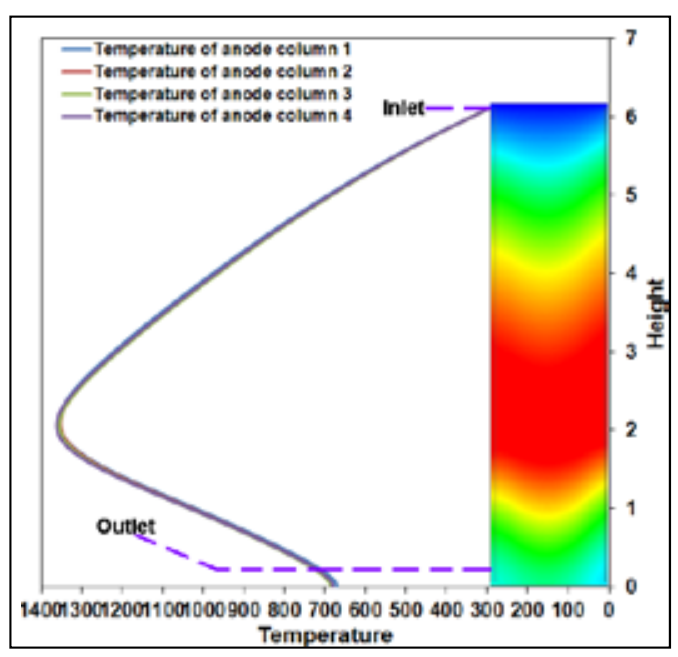

b

Fig. 6. CFD simulation temperature contours across four anode columns (a) and temperature along each column centerline (b)

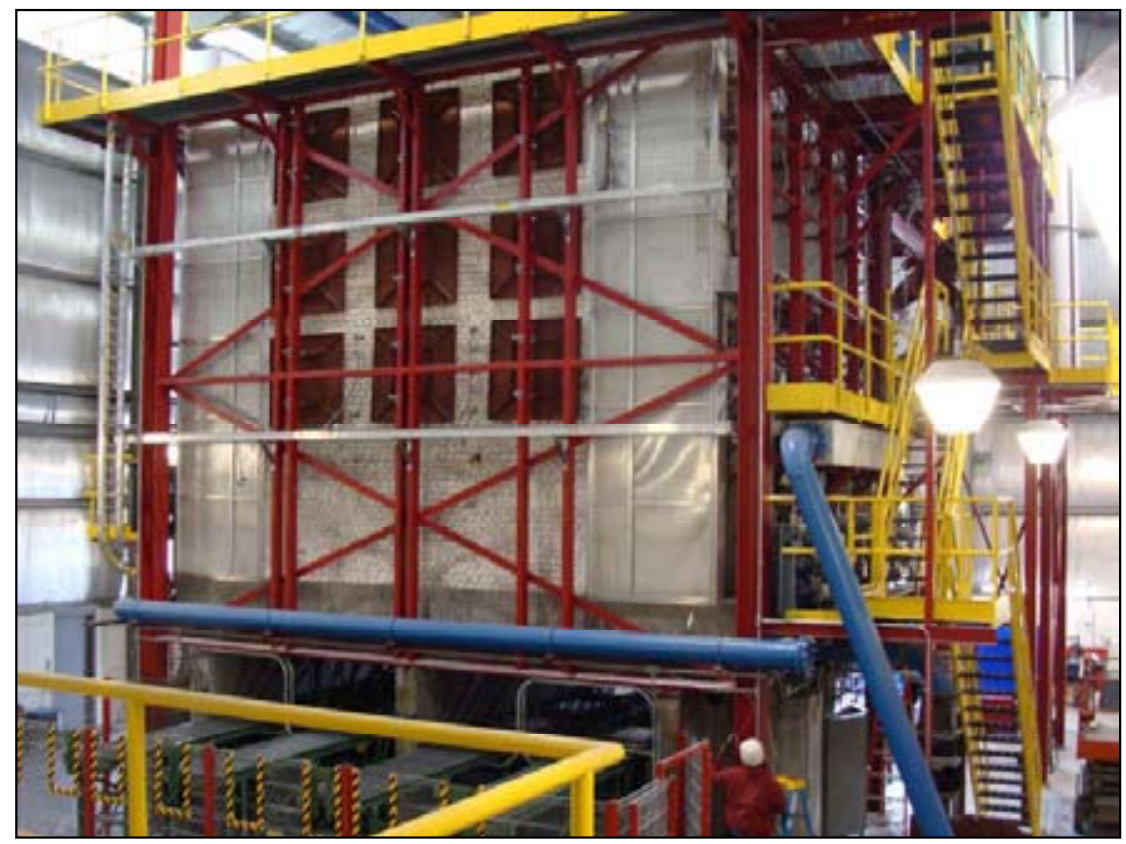

Fig. 7. Lazar CCBF Hawesville, KY prototype furnace 
the performance of the full-scale continuous process. The facility has successfully baked green anodes, using the data gathered during the process to fine-tune and improve current and future designs.

\section{Conclusion}

The global aluminum industry is continuously seeking new ways to refine and improve the methods in which it operates. Environmental restrictions and cost factors play a crucial role in the development and implementation of new technology. The Lazar CCBF offers solutions to many of the problems facing primary aluminum production. A flexible and modular design, coupled with steadystate operation and a high degree of automation, results in a process with a lower environmental impact and reduced costs.

\section{References}

[1] Moors E.H.M. Technology strategies for sustainable metals production systems: a case study of primary aluminium production in The Netherlands and Norway, Journal of Cleaner Production. 2006. Vol. 14, 1121-1138

[2] Mannweiler U., Fischer W.K., Perruchoud R.C. Carbon Products: A Major Concern to Aluminum Smelters, Light Metals. 2009, 909-911

[3] Lazarou R. et al. A New Concept for Baking Anodes - Initial Full-Scale Test Results \& Future Potential, Light Metals. 2009, 1021-1026

[4] Keller F., Sulger P.O., Fischer W.K. Anode Baking: The Underestimated Human Aspect, Light Metals. 2009, 1015-1020

[5] Neill D. The anode baking revolution, Aluminum International Today. 2015. Vol. 27. N. 3.

[6] Zhou Y. et al. CFD Thermal Modeling of the Anode Baking Furnace, 2nd Asian-US-European Thermophysics Conference in Hong Kong. 2012. 